\title{
LETTERS
}

\section{Questions on analysis of firearm injuries study}

Your article ${ }^{1}$ has been making headlines across the province, congratulations. It appears as though the media are focusing on what is being referred to as an important problem with firearms safety in Ontario and the country.

As an avid sports shooter in Ontario, I am wondering if you could provide some further information on your analysis? Can you provide a summary of the data relating to the types of firearms injuries? I note in the appendices that there are several codes (W34, X95, X74 and Y24) that refer to injuries from other types of firearms including BB guns or pellet rifles. Do these codes also include paint guns, airsoft rifles, slingshots and other implements that shoot or launch projectiles? If so, could you identify in a comprehensive list all firearms included in the research, and what their statistical signifi- cance is in the study (i.e., do injuries from these types of firearms equate to $3 \%, 10 \%$, $15 \%$, etc. of the injuries analyzed)? Was there a determination for the purposes of your study that only those injuries caused or related to firearms that are legally classed as firearms in accordance with Section 2 of the "Criminal Code" were to be included? Did your research include bows and crossbows in its analysis? Also, what are the types and extents of the injuries in the study?

The general public seems to assume that the study focused solely on shootings, which may be the case, but it isn't readily apparent to the general reader. Are the injuries analyzed actually all gunshot wounds? Or do they include all types of injuries resulting from proper or improper use of a firearm? If so, what is the statistical relevance of each type of injury? How do the findings of this study relate to other findings of child-related injury in Canada? By this, I mean what is the statistical significance of one injury per day compared with trip and fall injuries, toppling furniture, injuries from sharps or flames, physical altercations, poisonings, drownings, etc.?

Thank you for considering my request. As an avid member of the sports shooting community, I want to ensure that I fully understand the parameters of the study so that meaningful discussions can be had.

\section{Jay McGuffin}

London, Ont.

Cite as: CMAJ 2017 May 29;189:E752.

doi: $10.1503 / \mathrm{cmaj} .733005$

\section{Reference}

1. Saunders NR, Lee H, Macpherson A, et al. Risk of firearm injuries among children and youth of immigrant families. CMAJ 2017; 189: E452-8.

Competing interests: Jay McGuffin is a sport shooter. 